\title{
Cultura de los cuidados: el debate entre historia y enfermería pre-profesional en las acuarelas de Jean-Baptiste Debret (1816-1831)
}

Culture of care: the debate between history and pre-profissional nursing in watercolors of Jean-Baptiste Debret (1816-1831)

Cultura dos cuidados: o debate entre história e enfermagem pré-profissinal nas aquarelas de Jean-Baptiste Debret (1816-1831)

Paulo Fernando de Souza Campos

Doutor em História com Pesquisa de Pós-Doutorado em História da Enfermagem pela Escola de Enfermagem da Universidade de São Paulo - EE/USP/FAPESP. Professor do Programa de Pós-Graduação Interdisciplinar em Ciências Humanas da Universidade de Santo Amaro - UNISA.

Cómo citar este artículo en edición digital: Campos, P. F. S. (2015). Cultura dos cuidados: o debate entre história e enfermagem pré-profissinal nas aquarelas de Jean-Baptiste Debret (1816-1831)

Cultura de los Cuidados (Edición digital), 19(43). Disponible en: $<$ http://dx.doi.org/10.14198/cuid.2015.43.10>

Correspondencia: Rua Isabel Schmidt, 349, Santo Amaro, São Paulo, Brasil. CEP 04743-030.

Correo electrónico: pfcampos@unisa.br

Recibido: 07/07/2015; Aceptado: 5/11/2015

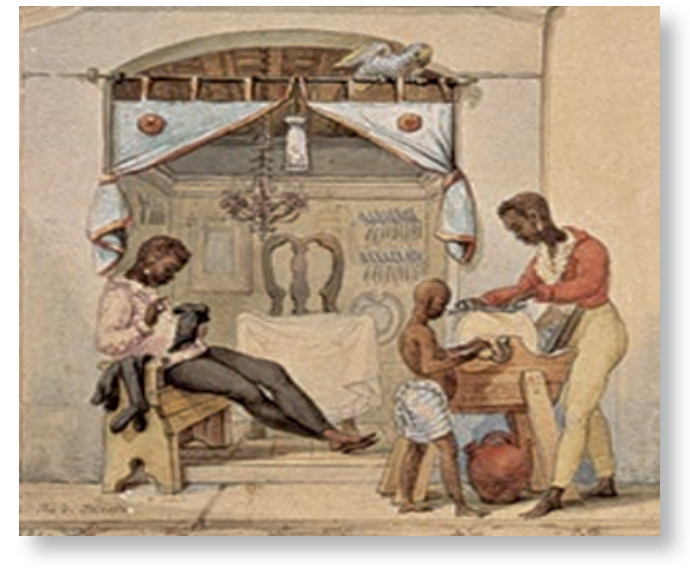

ABSTRACT

To identify practices to care for and cure performed by black men and women, the study evokes the historical context marked by the transfer of the Portuguese Crown (1808-1820) to Brazil, social space meant as conducive to the development of diseases. Legacy pictorial records of the work of Jean-Baptiste Debret, preserved in the Museum Castro Maya, Rio de Janeiro, were used as the source and the results are social places of care and its performers as well as the links between History and History of Pre-Professional Brazilian Nursing in their oblique relations with the culture of care.

Keywords: Culture Care; Cultural History; Pre-Professional Nursing; Negros

\section{RESUMEN}

La identificación de las prácticas de cuidar y curar realizadas por hombres y mujeres negros, permitio el estudio del contexto histórico marcado por la transferencia de la Corona Portuguesa (1808-1820) para Brasil, espacio social significado como propicio para el desarrollo de enfermedades. El registros pictóricos legados de la obra de Jean-Baptiste Debret, conservados en el Museo Castro Maya, Rio de Janeiro, fueron utilizados como fuentes de la investigación y los resultados apresentan lugares sociales de atención a la salud y sus executores, así como los vínculos entre Historia e Historia de la Enfermería Pre-Profesional brasileña en sus relaciones oblicuas con la cultura del cuidados. 
Palavras-Clave: Cultura de los Cuidados; Historia Cultural; Enfermería Pré-Profesional; Negros.

\section{RESUMO}

Ao identificar práticas de cuidar e curar realizadas por homens e mulheres negros, o estudo evoca o contexto histórico marcado pela transferência da Coroa Portuguesa (18081820) para o Brasil, espaço social significado como propício para o desenvolvimento de doenças. Os registros pictóricos legados da obra de Jean-Baptiste Debret, preservados nos Museus Castro Maya, Rio de Janeiro, foram usados como fonte e os resultados apresentam lugares sociais do cuidado e seus executores, bem como os nexos entre História e História da Enfermagem Pré-profissional brasileira em suas relações oblíquas com a cultura dos cuidados.

Palavras-Chave: Cultura dos Cuidados; História Cultural; Enfermagem Pré-Profissional; Negros.

\section{INTRODUÇÃO}

No início do século XIX, com a instalação da família real portuguesa na Colônia brasileira, escolas de medicina são fundadas no Brasil. $\mathrm{O}$ fato se mostra decisivo para a adoção de uma nova representação de saúde em um ambiente físico e social cujo clima, alimentação, costumes e paisagens, além de diametralmente opostos aos do mundo europeu, caracterizavam o local como propício para o desenvolvimento de doenças. Assim, os cuidados com a saúde deveriam atingir a camada melhor posicionada economicamente da população, que valorizava a prática da medicina acadêmica, de origem predominantemente portuguesa e claramente influenciada por valores positivis- tas. Entretanto, práticas populares executadas por homens e mulheres negros constituíam a possiblidade de cuidado e cura mais acessível e que surtia melhores resultados (Malerba, 2000; Abreu, 2007).

Mesmo com a progressiva afirmação da Medicina, práticas culturais e antropológicas de cuidado e cura não deixaram de ter importância social uma vez que continuavam a serem utilizadas não somente por quem não dispunha de condições financeiras para pagar consultas médicas, mas pela desconfiança da competência de médicos portugueses na manutenção da vida e diminuição de sofrimentos (Ribeiro, 1997). A existência simultânea das duas possibilidades de saberes sobre os corpos doentes proporcionou uma realidade diversa de práticas de cuidado e cura, cujo alcance se constata nos dias atuais, em vivências que se interpõem à perspectiva dominante, bem como na constante busca pela compreensão de sua historicidade (Figueiredo, 2002).

Nesse sentido, a História, compreendida não mais como narrativa linear e evolutiva dos acontecimentos, redimensionou fatos considerados incontestes ao desdobrar o passado conhecido e seus impactos na vida das pessoas. As novas perspectivas recuperaram autores relegados pela historiografia dominante e multiplicaram estudos históricos fundados na interdisciplinaridade, cujas abordagens provocaram o encontro de saberes distintos, correlatos ou não, mas com interesses convergentes. Os resultados permitiram reconhecer novos objetos, problemas e novas abordagens na interpretação do tempo histórico, assumido não mais como pronto e acabado, mas como processo, assim, em constante transformação e movimento (Le Goff, 1990).

Temas considerados menores, marginais ou evocados da vida cotidiana, a partir de fon- 
tes não oficiais, mas provenientes de acervos desprestigiados ofereciam aos 'novos' historiadores a possibilidade de uma escrita diametralmente oposta ao que vigorava no século XIX como legitima e científica. Interessados nas práticas cotidianas e experiências de homens e mulheres comuns, estudos históricos ampliaram o diálogo interdisciplinar e avançaram nos domínios da História como, neste caso, as abordagens propostas pela antropologia médica, cultura dos cuidados e história da enfermagem pré-profissional, as quais se associam ao debate da história cultural, praticada de acordo com Peter Burke (1992) há mais de duzentos anos na Alemanha (Kulturgeschichte). Portanto, não se trata de algo novo.

A associação entre campos disciplinares como avaliou Clifford Geertz, antropólogo norte-americano que inspirou historiadores culturais, implica pensar o “[...] padrão historicamente transmitido, de significados incorporados em símbolos, um sistema de concepções herdadas, expressas em formas simbólicas, por meio das quais os homens se comunicam, perpetuam e desenvolvem seu conhecimento e suas atitudes acerca da vida" (Geertz, 1989, p.89). O intuito dos estudos que emergem dessa matriz teórico-metodológica é reiterar a presença de redes de valores que se internalizam e são reproduzidos por indivíduos e coletividades como naturais ou correlatos de verdade, quando invariavelmente é produzida para a manutenção de ideologias e mentalidades dominantes.

A perspectiva permite considerar que concepções de saúde e doença como de cura e cuidado são construções sociais, logo, permeadas por intencionalidades datadas e caracterizadas por contextos históricos específicos, dos quais emergem interesses políticos, institucionais, econômicos, sociais e de gênero. Suas repre- sentações se alteram no tempo e explicam a existência da realidade humana, porém, assumidas na forma de conceitos universais, ditos positivos ou estabelecidos por critérios rigidamente propostos, minimizam a contribuição das ciências humanas como balizadora dos processos, mesmo os técnicos.

Ocorre que na História o estabelecimento de conceitos não se dá como definição imutável ou sem interesses de grupos que se interpõem e atribuem significados às práticas sociais (Chartier, 1991). O diálogo necessário, mas pouco estabelecido, impede o reconhecimento de mudanças, reconfigurações, impactos e permanências nas esferas de atuação historicamente constituídas - no caso, dos enfermeiros - por desprestigio ou desconsideração de campos disciplinares compreendidos em oposição ou menores na escala utilizada como referência. Ainda que estudiosos da história da enfermagem pré-profissional, norte-americanos e europeus, reconheçam relações de interdependências entre os campos disciplinares, no Brasil, interdisciplinaridade e uso de corpus teórico-metodológico diverso do oficial constituem-se enquanto espaços em aberto para a produção de um conhecimento ainda a ser explorado (Donahue, 1996; Soares, 1997; Siles-Gonzales, 1999; Viterbo, 2012).

A reconfiguração da escrita da História possibilitou o desprendimento de determinismos impostos por datações rígidas, oficializadas por modelos demarcadores de uma história linear e progressiva, vale dizer, os estudos históricos avançaram nas diferentes temporalidades. No caso específico, tal procedimento permite reconhecer nas práticas de cuidar e curar exercidas no Brasil Colônia a identificação de permanências, transformações e rupturas de interesses comuns, isto é, tanto para historiadores, quanto para enfermeiros. Neste 
sentido, o presente artigo investiga práticas de cuidar e curar anteriores a profissionalização do cuidado, considerando-as nos domínios das ações executadas por agentes não profissionais, portanto, analisando-as como parte do processo histórico, cultural e antropológico do cuidar e curar no Brasil.

Partindo desses pressupostos, a pesquisa ora apresentada utilizou como corpus as aquarelas de Jean-Baptiste Debret pintadas durante sua permanência no Brasil (1816-1831). Cabe destacar que o uso da fonte imagética, por se inscrever no campo do imaginário, encontrou resistência entre historiadores, pois parecia não informar o real, mas "[...] uma fissura entre real e imaginário (ilusório, quimera, sonho), colocando dessa maneira obstáculos ao uso dessa fonte pelo historiador uma vez que o seu ofício definia-se em torno do acontecido e não de elaborações que se inscreviam no campo das representações" (Silva, 1996, p.43).

Ressalta-se, entretanto, que não se trata de uma reflexão sobre a arte, dos elementos artísticos e das técnicas de pintura, tampouco, das problemáticas que envolvem a história dos viajantes, mas da identificação de práticas de cuidar e curar exercidas no Brasil Colônia, seus executores e locais nos quais foram retratados. Do mesmo modo, o tratamento ao tema possibilita criticar o uso da História como metodologia, o que invariavelmente desqualifica ou ignora diferentes dimensões históricas, no caso, a dimensão pré-profissional da arte e ciência do cuidado, modernamente identificada como Enfermagem.

As aquarelas utilizadas foram intituladas por Jean-Baptiste Debret como Boutique de Barbier, Les Barbiers Ambulants e Laguna vue de L'Hôpital, pintadas entre 1821 e 1828, cujos originais encontram-se preservados nos Museus Raymundo Ottoni de Castro Maya/
IBRAM/MinC, Rio de Janeiro, que mantém a Coleção Brasiliana. As análises foram empreendidas a partir de pressupostos da História Cultural como os que contemplam a complexidade do tempo histórico, a diversidade das práticas e representações inscritas no cotidiano e as pessoas comuns como fundamento teórico-metodológico para a construção da narrativa histórica.

\section{Negros como cuidadores: as raízes do cuidado no Brasil}

Base da sociedade colonial brasileira, a escravidão de africanos serviu como modelo para o constructo de sociabilidades ascendentes em um sistema social forjado na violência, característica do longo período Colonial que recobre a politica escravocrata no Brasil. Durante quatro séculos de história oficial as mentalidades existentes significavam os negros a partir da escravidão. Ser negro no Brasil implicava naturalmente ser escravo, constituindo-se como condição inexorável, pois ainda que libertos ou alforriados eram desclassificados moral, social e fisicamente (Schwarcz, 1993).

Mesmo considerando a existência de enriquecimento, a maioria negra foi discriminada, posta à margem da sociedade colonial. Suas experiências - explícitas ou subterrâneas - foram desconsideradas pela historiografia. A dupla exclusão, entretanto, não impedia resistências e participações cotidianas na vida colonial, mas ao contrário, como revelou a história social produzida no Brasil na década de 1980. Os estudos históricos derivados reconfiguraram o cotidiano das populações negras e destituíram a hegemonia de modelos teórico-metodológicos que os representavam como escravo-coisa ou mercadoria, significando-os como ignorantes, desajustados e doentes. A historiografia brasileira (Chalhoub, 1996; Or- 
tiz, 1994) desmontou representações anteriores ao desvelar os negros em experiências, não raro, que os anunciavam em condições de luta e sobrevivência criativas. A historiografia rompia com as análises esquemáticas fundadas em lógicas dissonantes.

O movimento transatlântico da Cora Portuguesa para o Brasil (1808-1820), promovido pela fuga da Família Real das tropas de Napoleão Bonaparte (1769-1821), implicou a interferência significativa de regras de comportamento e valores novos trazidos pela Cora, entre os quais, os que atingiam práticas cotidianas de cuidado, tratamento, cura de doenças e moléstias físicas e mentais. Raramente mencionados, personagens anônimos, os cuidadores pré-profissionais do Brasil colonial foram sufocados por uma escrita estanque sobre a história da enfermagem brasileira. Negros eram cuidadores em potencial no longo período que recobre a sociedade colonial brasileira.

A transferência da Metrópole para a Colônia acarretou profunda alteração na rotina dos diversos grupos sociais da cidade do Rio de Janeiro. Aproximadamente 15 mil pessoas desembarcaram em seus portos e, nesse processo, não somente mudanças políticas e econômicas resultaram de tal empreendimento, mas alterações culturais, que impactaram nas formas de sobrevivência dos homens e mulheres reinóis, brancos e negros. Três classes sociais foram formadas na Corte com pouca possibilidade de mudança. Em primeiro plano os membros da Corte, seguidos da elite fluminense formada por comerciantes abastados, na base da sociedade colonial a população predominante negra e escravizada. Desse processo emerge uma complexa rede de interdependências, que permeia o novo arranjo social e no qual se constatava a necessidade de estabelecimentos de laços sociais para o alcance de variados in- teresses como afirma Jurandir Malerba (2002), entre os quais o cuidado, a cura.

$\mathrm{Na}$ esteira das mudanças, práticas dedicadas ao cuidado do corpo enfermo realizadas secularmente permaneceram efetivas na sociedade brasileira. Entre as mulheres negras existiam as que se tornavam reconhecidas e requisitadas por suas habilidades como parteiras, amas-de-leite, benzedeiras, mães pretas (Souza Campos, 2008). Inseridas em uma sociedade patriarcal e escravocrata, a eventual capacidade de intervir positivamente ante um sofrimento físico - ou espiritual - conferia aos que detinham tal conhecimento posição de destaque social, de considerável vantagem em um mundo fundado na submissão, mas também na resistência. Ainda assim, conflitos gerados pelo medo de contágio de moléstias, que supostamente albergavam corpos negros, ampliavam os rigores. As recusas atingiam principalmente mulheres que atuavam da porta para dentro, no interior das casas coloniais, constantemente vigiadas (Mott, 1991; Graham, 1992).

O debate torna-se procedente se avaliado em relação à formação de uma nova história da enfermagem. A presença negra no cuidado desvela um dos traços marcantes da sociedade colonial brasileira, qual seja, “[...] a lenta mas constante proximidade com as famílias dos senhores [...] Coube às babás e mas de leite, cuidadosamente escolhidas entre as famílias negras, promover essa proximidade, ao serem encarregadas de cuidar dos filhos de seus senhores" (Ermakoff, 2004, p.98). O não reconhecimento da participação afrodescendente no processo histórico do cuidado no Brasil contribui para reafirmar imagens sociais perpetuadas, que os desqualificam.

As prerrogativas permitem considerar que sociabilidades fundadas na dualidade 
superior/inferior atingiram a orientação e o exercício profissional dos enfermeiros, cujos impactos reverberam educação, trabalho $e$ orientação profissional na medida em que atravessa o saber-fazer, pois interferi na assistência prestada e prejudica competências e habilidades inerentes ao exercício profissional como comunicação, relacionamento interpessoal, equidade, empatia, tolerância, poder de decisão, reflexão, problematização e transversalidade, temas pontuados nas diretrizes para formação superior em Enfermagem no Brasil (Brasil, 2001).

Um dos sentimentos gerados pode ser reconhecido como racismo, que sustenta a discriminação em relação a indivíduos considerados de outra raça/etnia. Não somente no Brasil, como em outros países, o racismo age como mecanismo utilizado por grupos considerados superiores, para justificar a dominação de uns sob outros com a finalidade de satisfazer interesses, hierarquizar relações e excluir o diferente/divergente (González, 1990). No caso brasileiro, as vicissitudes da escravidão são exemplares do processo danoso provocado pelo racismo.

A conduta, fortalecida pela noção de hereditariedade, inferioridade em relação ao branco, impunha uma representação desqualificadora aos afrodescendentes. Todavia, nas aquarelas de Jean-Baptiste Debret os negros são identificados em suas atuações no âmbito das práticas de cuidar, cuidado e cura. Como destacado, mulheres negras no Brasil Colônia agregavam em suas práticas cotidianas o trabalho de parteira, cuidadoras de idosos e crianças, sãos ou doentes, nutrindo-os não apenas no peito, mas produzindo seu alimento, cuidando de sua dieta e saúde (Souza Campos, 2008). Vale dizer, os negros aturam como precursores pré-profissionais da arte e ciência do cuidado no Brasil e a primazia da mulher negra não era diferente nas Américas como permite considerar a trajetória de Mary Seacole, reconhecida e condecorada na Inglaterra Vitoriana como Florence Negra por sua atuação na Batalha de Sebastopol durante a Guerra da Criméia (1856-1865). No caso brasileiro, antes da profissionalização, homens e mulheres negros assumiam as funções sociais que hoje são realizadas sistematicamente por enfermeiros.

\section{Cuidadores Negros nas Aquarelas de Jean- -Baptiste Debret}

As práticas de cuidar e curar expressas nas obras do pintor francês considerado um dos principais narradores da vida cotidiana colonial brasileira destacam seus executores. A produção legada da permanência do pintor no Brasil é avaliada um dos mais importantes registros da experiência dos negros durante a permanência da Corte nos trópicos. Estudiosos da técnica de pintura identificada como aquarela indicam que Debret antes de pintar desenhava esboços de aspectos específicos do que via nas cenas e personagens do cotidiano, isto é, de forma esparsa e isolada, cuja posterior justaposição resultava no quadro final. Seu método era a construção do todo pelo detalhe.

Jean-Baptiste Debret chegou ao Brasil em 26 de março de 1816 integrando a Missão Artística Francesa que fundou no Rio de Janeiro a Academia de Artes e Ofícios, definida por Júlio Bandeira (2006) como uma colônia de artistas bonapartistas no ostracismo. Na ocasião, o então professor de desenho e futuro diretor da Academia encontrava-se amargurado, solitário e exilado, sem expectativas e com problemas pessoais. A familiaridade com a pintura de cunho histórico e a pers- 
pectiva da mudança radical de sua condição motivou-lhe a ingressar na longa travessia do Atlântico e após dois meses de viagem chegou a Baía de Guanabara, na cidade do Rio de Janeiro, imagem que descreveu como uma das maravilhas do mundo. Ao se encantar pela profusão da paisagem: “[...] o aspecto de abundancia universal, a vegetação desconhecida, o colorido absolutamente novo para os olhos europeus o fizeram a desenhar quase que imediatamente [...]" afirma Ana Paola Baptista (2011, p. 10).

Jean-Baptiste Debret era membro de uma família de pintores e sua vida é marcada por sucessos nos salões europeus com pinturas históricas de cunho neoclássico, produtos de encomendas que recebia do governo napoleônico para obras celebratórias (Baptista, 2011). No Brasil, além da pintura histórica, Debret retratou a vida cotidiana na cidade do Rio de Janeiro e fora dela. Por esse motivo, sua obra é considerada um inventário enciclopédico da realidade brasileira à época.

Sintomaticamente, Jean-Baptiste Debret em sua obra apresenta homens negros identificados como barbeiros, sangradores, dentistas e outros cuidadores. De acordo com a historiografia consultada, não raro o trabalho dos cirurgiões - não havia mulheres no ofício - era compartilhado e indicado por médicos portugueses, que receitavam tratamentos dispensados por desconhecimento de determinados procedimentos ou pela eficácia dos mesmos. Conforme aponta Betânia Gonçalves Figueiredo (2002) os homens negros detinham o conhecimento de intervir no corpo ulcerado, nas pústulas, nas doenças da pele, no trato de membros quebrados como pernas e braços, na diminuição de dores, além de se ocuparem da higiene bucal, do cuidado dos dentes e das extrações, no trato dos cabelos e das unhas, além das rezas que aliviavam as dores da alma. Para tanto utilizavam ervas, sangrias, fumos, banhos e manipulavam instrumentos construídos para as finalidades propostas: cuidar e curar (Ribeiro, 1997; Betânia, 1999).

Dentre as aquarelas pintadas por Debret, expostas e publicadas no livro Viagens ao Sul do Brasil, três registros permitem considerar as práticas de cuidar e curar como ações exercidas por negros. A consideração reitera aspectos de interesse para a cultura dos cuidados e antropologia médica no Brasil, pois desvelam práticas e agentes do cuidado anteriores aos padrões estabelecidos como demarcadores para os processos históricos no campo da Enfermagem. O interesse se amplia com a constatação política de que na sociedade escravocrata o trabalho dedicado ao cuidado era executado por homens e mulheres negros, pois redimensiona a historicidade brasileira do saber considerado como o mais elegante das ciências modernas.

A profundidade das marcas deixadas pela escravidão no Brasil significava a população negra como destituída de organização ou conhecimento próprio e a historiografia os narrava a partir da inferioridade e depreciação de suas ações, mesmo após a abolição em 1888 . Deste modo, o estudo das aquarelas de Jean-Baptiste Debret é uma possibilidade de evidenciar práticas executadas por negros no âmbito do cuidado no século XIX, bem como a importância dessas ações para o desenvolvimento da sociedade brasileira e dos estudos históricos da enfermagem pré-profissional. A primazia de suas práticas, cujas ações incluíam a manutenção da higiene pessoal, alimentação, repouso, tratamento de doenças graves ou não, prevenção, acompanhamento e auxílio de pessoas enfermas como realização de pequenas cirurgias, partos e amputações de membros le- 
sionados, foram primordiais para a manutenção da saúde no Brasil. Ainda que o material documental utilizado apresente aspectos sutis, tais vestígios não são menos reveladores da memória histórica e antropológica do cuidado como permite considerar o paradigma indiciário fundado na investigação de pequenas pistas e sinais (Guinzburg, 1989).

Importantes para a vida em comum, a existência de cuidadores negros em uma sociedade escravocrata reverbera a proverbial desqualificação e ineficácia dos tratamentos executados por médicos portugueses (Ribeiro, 1997). A aquarela 1, identificada como Barbeiros ambulantes, remonta uma cena urbana, que mescla o encontro de pessoas, o comércio de rua e a chegada de navios no porto do Rio de Janeiro, assim, representa a Corte como um local de negociações constantes com o velho mundo e de fluxo interrupto de valores e pessoas.

A aquarela evidencia negros barbeiros pobres cuidando de outros negros também pobres. Nessa aquarela o autor retrata o cuidado como atividade aplicada a todos os residentes, permitindo supor a importância dos serviços prestados e a necessidade social de seus executores. Desse modo, desvela a complexidade da existência negra no Brasil, assim como suas resistências aos imperativos que os desqualificavam.

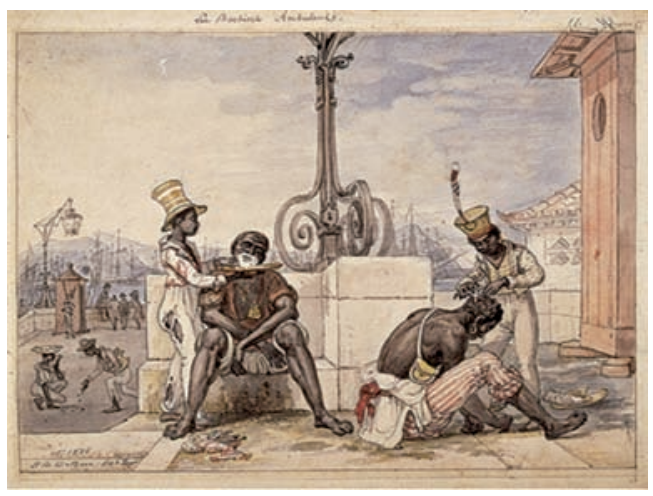

AQUERELA 1 - BARBEIROS AMBULANTES
Nessa aquarela, pintada em 1826, a condição social dos barbeiros é revelada nas vestimentas rotas, velhas e rasgadas. Ainda assim, o artista pontua a circularidade cultural vivida na Corte ao retratá-los com chapéus e outros adornos em bom estado de conservação, porém, de segunda mão, originalmente fabricados para outros fins e usos. Em contraste com as demais peças da indumentária, as quais se assemelham às roupas dos usuários, os chapéus são indicativos de uma rede social complexa, pois permitem considerar as sociabilidades entre os diferentes personagens que viveram a estadia da Corte no Brasil.

Os adornos sugerem trocas simbólicas alcançadas por esses cuidadores, ao mesmo tempo em que o oficio praticado em via pública e a céu aberto permite considerar a utilidade, importância e mobilidade desses homens na vida das pessoas ricas ou pobres. A aquarela indica ainda que a população pobre e trabalhadora necessitava e mantinha a higiene pessoal e o asseio, práticas reveladoras da cultura dos cuidados entre os negros e por eles preservadas, o que contribui para redimensionar interpretações unilaterais que os identificavam como sujos e disseminadores de doenças.

A aquarela 2, identificada como Loja de barbeiros, supostamente pintada anos antes, em 1821, retrata cuidadores na cidade do Rio de Janeiro em situações diametralmente opostas. Nessa aquarela o pintor amplia as considerações sobre a organização e divisão dos serviços de saúde para pobres e ricos, pois apresenta um estabelecimento público, comercial, destinado à cura e ao cuidado de pessoas enfermas. O estabelecimento retratado na aquarela desvela um local limpo, organizado, provido de instrumentos de corte e utensílios usados na preparação de remédios e intervenção do corpo doente. 




AQUERELA 2 - LOJA DE BARBEIROS

Nos dois casos, os negros figuram como cuidadores. Contudo, na aquarela 2, ao representar três homens negros em atividade de manutenção dos equipamentos - além de uma escrava de ganho e uma senhora branca - o pintor revela a existência de uma organização do trabalho, sugerindo a existência de equipe e hierarquia entre seus executores, além da existência de um espaço físico: a loja. A comparação entre a Loja de Barbeiros e Barbeiros Ambulantes evidencia tanto a distinção dos serviços prestados, quanto a participação efetiva de negros nas práticas de cuidado e cura no Brasil do século XIX, em diferentes condições de trabalho e identidades. A aproximação entre a loja de barbeiros e a casa de uma mulher branca, em cuja cena é retratada comprando produtos vendidos por uma escrava de ganho, permite supor que se tratava de um local da cidade habitado por pessoas abastadas, logo, que os negros não estavam alheios as diferenciações de classe, hierarquia social e outros distintivos, inclusive, internamente.

A obra de Debret desvela uma complexa participação de negros na vida social durante a permanência da Corte do Brasil. A aquarela 3, pintada em 1828 e intitulada Vista do hospital, Florianópolis, se destaca das demais por retratar a vida fora da cidade do Rio de Janeiro, mas a cidade de Desterro, então capital do Estado de Santa Catarina, região sul do Brasil. Nessa aquarela, Debret permite verificar o exercício do cuidado realizado por negros em um espaço hospitalar como confirmam alguns detalhes miniaturizados presentes na pintura, os quais revelam um doente sendo carregado em uma rede por dois negros e o que parece ser uma criança, que ampara um homem branco com uma das pernas enfaixada e usando muletas, elementos que permitem as considerações em pauta.

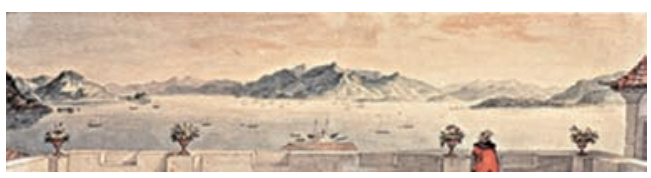

AQUERELA 3 - VISTA DO HOSPITAL, FLORIANÓPOLIS

Não obstante, as evidencias do cuidado nas obras de Debret revelam a existência de um legado cultural afrodescendente no âmbito da enfermagem pré-profissional brasileira. As aquarelas não somente destacam os negros em práticas de cuidar e curar, mas apontam para a fabricação de redes de sociabilidades complexas e diferenciadas, traduzidas pela antropologia médica e cultura dos cuidados como formas de cuidar e curar anteriores ao surgimento de escolas e da profissionalização ou do modelo vitoriano de formação. As aquarelas pintadas por Jean-Baptiste Debret comprovam a primazia das ações realizadas por homens e mulheres negros, cujas origens culturais remontam práticas ancestrais. Sua obra desvela a importância dos negros na vida social brasileira, sobretudo, redimensiona suas existências e representações na formação dessa mesma sociedade, sintomaticamente, como agentes na constituição da longa história da enfermagem pré-profissional no Brasil.

A forma de análise das práticas de cuidar e curar executadas por negros no contexto, por 
suas características próprias, implica considerar o debate em torno da formação histórico-cultural do cuidado no Brasil, vale dizer, em suas diferentes temporalidades e perspectivas históricas. O cotejamento das fontes com as referências possibilitou evidenciar a participação dos negros nesse processo, destacar as experiências do cuidado em sua dimensão pré-profissional, ou seja, consideradas não como produto da institucionalização de espaços de formação, mas como experiência exercida no processo histórico.

Os usos da História pela Enfermagem invariavelmente desconsideram ações anteriores aos marcos simbólicos instituídos por uma escrita linear que impõe uma historicidade única, unilateral. No caso específico, o surgimento de modelos profissionalizantes é considerado como marco para a historicidade, no caso brasileiro, construído no padrão dominante de ensino e formação profissional. Destarte, o estudo reitera que a História não é um método ou uma ferramenta de pesquisa e que se utilizada como metodologia, deixa de reconhecer no tempo contextos, agentes e práticas.

Ao partir de uma delimitação incompatível com a densidade da História e por destituí-la do debate teórico, estudos históricos oriundos da Enfermagem interpretam o tempo de suas ações a partir de maniqueísmos que fabricam histórias ilustres, sempre vencedoras. Ainda que destaquem as mulheres, estas são representadas no exercício do poder e pela via do discurso dominante, vinculadas às instituições de ensino, militares ou evocadas em postos de comando, cujas trajetórias são analisadas progressivamente, em oposição ao masculino, cujo gênero é avaliado subalternamente em relação a sua principal personagem: a enfermeira. $\mathrm{O}$ não reconhecimento da densidade histórica impede o desenvolvimento de po- tencialidades investigativas na medida em que restringe a historicidade das práticas de cuidar e curar a um recorte unidirecional e hermeticamente fechado.

\section{BIBLIOGRAFIA}

- Abreu, J. L. N. (2007). A Colônia enferma e a saúde dos povos: a medicina das 'luzes' e as informações sobre as enfermidades da América portuguesa. Hist. cienc. saudeManguinhos, 14(3), 761-778.

- Bandeira, J. (2006). Jean-Baptiste Debret: Caderno de viagem. Rio de Janeiro: Sextante Artes.

- Batista, A. P. (2011). Debret: Viagem ao Sul do Brasil. Rio de Janeiro: Memória Visual.

- Brasil. Resolução CNE/CES no 3, de 7 de novembro de 2001. Institui Diretrizes Curriculares Nacionais do Curso de Graduação em Enfermagem. Recuperado de: $<$ http://portal.mec.gov.br/cne/arquivos/pdf/CES03. pdf $>$.

- Bordieu, P. (1983). Sociologia. São Paulo: Ática.

- Burke, P. (1992). A Escrita da História. Novas perspectivas. São Paulo: Edunesp.

- Chalhoub, S. (1996). Cidade Febril. Cortiços e epidemias na corte imperial. São Paulo: Companhia das Letras.

- Chartier, R. (1991). O Mundo como Representação. Estudos Avançados, 5(11), 173-191.

- Debret, J-B. (2010). Viagem pitoresca e histórica ao Brasil. Belo Horizonte: Itatiaia.

- Donahue, P. (1996). Nursing, The Finest Art. An Illustrated History. St. Louis: Mosby.

- Ermakoff, G. (2204). O Negro na fotografia brasileira do século XIX. Rio de Janeiro: G. Ermajoff Casa Editorial.

- Freitas, M. V. de. (2012) Comadres e Matronas. Contributo para a História das Parteiras em Portugal (séculos XIII-XIX). Lisboa: Lusodidacta.

- Geertz, C. (1989). A Interpretação das Culturas. Rio de Janeiro: LTC.

- Ginzburg, C. (1989). Sinais. Raízes de um paradigma indiciário. En: Mitos, Emblemas e Sinais (pp. 143-180). São Paulo: Companhia das Letras.

- González, A. M. R. (1990). Estudios Médico-Sociales so- 
bre Marginalizados em la España del siglo XIX. Madrid: Ministerio de Sanidad y Consumo.

- Graham, S. (1992). Proteção e Obediência: Criadas e seus patrões no Rio de Janeiro (1860-1910). São Paulo: Companhia das Letras.

- Le goff, J. (1990). História Nova. São Paulo: Martins Fontes.

- Malerba, J. (2000). A corte no exílio: civilização e poder no Brasil às vésperas da independência (1808-1821). São Paulo: Companhia das Letras.

- Mott, M. L. de B. (1991). Submissão e resistência. São Paulo: Contexto.

- Ortiz, R. (1994) Cultura Brasileira \& Identidade Nacional. 5. ed. São Paulo: Brasiliense.

- Ribeiro, M. M. (1997). A ciência dos trópicos: a arte médica no Brasil do século XVIII. São Paulo: Hucitec.
- Schwarcz, L. M. (1993). O Espetáculo das Raças. Cientistas, instituições e questão racial no Brasil 1870-1930. São Paulo: Companhia das Letras.

- Siles Gonzáles, J. (2011). Historia de la Enfermería. Madrid: DAE-Paradigma.

- Silva, Z. L. da. (1990). Os Dilemas da Pesquisa: as fontes oficiais e a imagética. En Di Creddo, M. do C. S.; Alves, P. y C.R. Oliveira de. (Orgs.) Fontes Histórias (pp. 39-46). Assis: Programa de Pós-Graduação em História.

- Soares, M. I. (1997). Da Blusa de Brim à Touca Branca. Lisboa: Educa.

- Souza Campos, P. F. de. (2008) Los Negros y los Cuidados en las Familias de Brasil: una visión histórica e iconográfica. Cultura de los Cuidados - Revista de Enfermería y Humanidades, (24), 26-34.

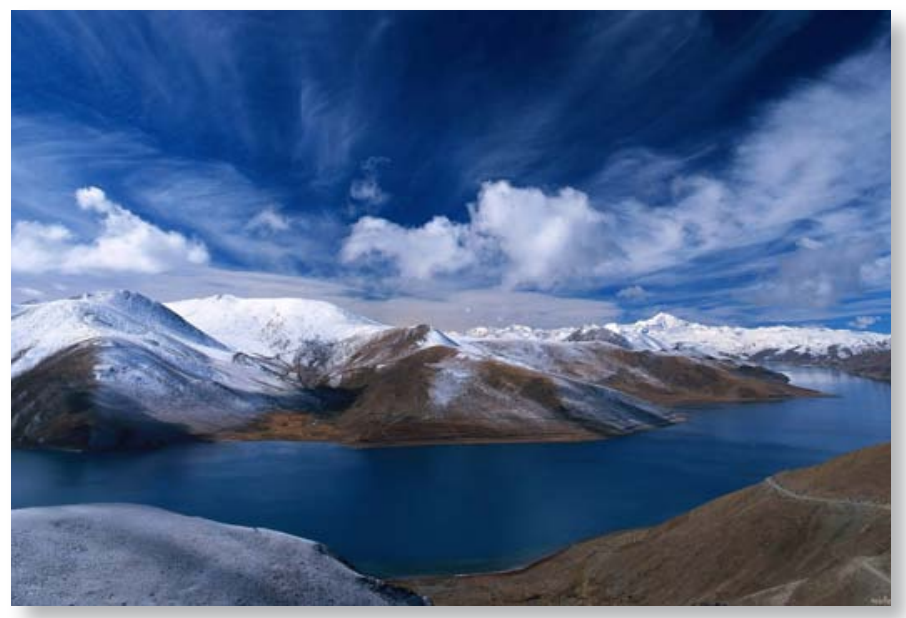

